4. In my memoir "On the production of light by heat" (Phil. Mag., May 1847), I established experimentally the following facts :-

(i) All solid substances and probably liquids become incandescent at the same temperature.

(2) The thermometric point at which some substances become red hot is about 977 Fahrenheit degrees.

(3) The spectrum of an incandescent solid is continuous; it contains neither bright nor dark fixed lines.

(4) From common temperatures nearly up to $977 \mathrm{~F}$., the rays emitted by a solid are invisible. At that temperature they are red, and the heat of the incandescing body being made continuously to increase, other rays are added, increasing in refrangibility as the temperature rises.

(5) Whilst the addition of rays so much the more refrangible as the temperature is higher is taking place, there is an augmentation in the intensity of those already existing.

This memoir was published in both American and European journals. An analysis of it was read in Italian before the Royal Academy of Sciences at Naples, July 1847 , by M. Melloni, which was also translated into French and English.

Thirtcen years subsequently $M$. Kirchhoff published his celebrated memoir "On the relations between the coeflicients of emission and absorption of bodies for light and heat." A translation of this memoir may be found in the Philosophical Magazine, July 1860.

In this memoir, under the guise of mathematical deductions, M. Kirchhoff, taking as his starting-point the condition discovered by Angström in 1854, respecting the relations between the emitting and absorbing powers of different bodies for light and heat, among other things deduces the following facts. I give them as they are succinctly stated by M. Jamin in his "Cours de Physique de l'école Polytechnique" (r869).

(I) All bodies begin to be red-hot at the same moment in the same space, and become white-hot at the same time.

(2) Black bodies begin to emit red rays near $525 \mathrm{C}$. (977 F.)

(3) The spectrum of solids and liquids is devoid of fixed lines.

(4) The rays first emitted by black bodies are red; to these are added successively and continually other rays, increasing in refrangibility as the temperature rises.

In his celebrated memoir, and in subsequent publications on the history of spectrum analysis, M. Kirchhoff abstains from drawing attention to the coincidences I an here pointing out, except that in a foot-note to his memoir he makes in a single word allusion to mine. But from this no one would infer what were really the facts of the case, and accordingly in the bibliographical lists subsequently published, in works on spectrum analysis, such as those of Prof. Roscoe and Dr. Schellen, my memoir is not noticed.

I earnestly solicit those who take an interest in the history of spectrum analysis to compare my memoir in the Philo. sophical Magazine, May 1847, with those published by M. Kirchhoff thirteen years subsequently, on the radiating and absorbing powers of bodies (Phil. Mag., July 1860), and on the history of spectrum a:talysis (Phil. Mag., April 1863).

University, New York, July 8 John William Drapek

\section{Sounding and Sensitive Flames}

In NATURE, vol. x. p. 223, Prof. Herschel describes some ex. periments recently made at the Newcastle College of Science, whereby sonorous vibrations are produced in tubes by means of heated wire-gauze instead of the ordinary gas flame. Interesting as are these experiments, they are, however, by no means new. The influence of heated wire-gauze in giving rise to vibrations of air within tubes was, I believe, first published by Prof. Rijke of Leyden. In Konig's catalogue for 1865, Rijke's tube is advertised (No. 27) and the method of experiment described. The readiest way of making the experiment is to cut a piece of the ordinary fine iron-gauze to the size of a sixpence or shilling, and press it some three inches up a glass tube of corresponding bore. Almost any length of tube over one foot may be employed, so that notes of varying pitch can be obtained. The gauze is easily heated by a little alcohol flame at the end of a bit of quill tubing. Employing platinum-gauze heated by an electric current, or a gas flame resting above the gauze, the sounds can be rendered permanent. By one or other of these methods no doubt many of your readers have, like myself, often repeated this experiment during the last six or seven years.
I notice also that Prof. Herschel has kindly attributed to me a modification of the ordinary sensitive flame; the credit of this belongs to Mr. P. Barry, of Cork. This arrangement simply consists of a sensitive flame burning on wire gauze, instead o directly from the gas jet. It was described in NaTuRE, vol. v. p. 3o, and some further experiments on this kind of flame are to be found in the journal of the Franklin Institute for April I872.

Perhaps it is not out of place to add here that when a sensitive flame under the influence of sound is viewed in a moving mirror, the state of its vibration, thus seen, reveals some interesting facts. Under such circumstances, the flame is capable of showing the nature of the different vowel sounds, and further, by the broken appearance of the flame one is able to detect sonorous vibrations too faint to be heard and too feeble otherwise to affect the flame. I have given a representation of the flame seen in a moving mirror on the plate appended to an article in the Popular Science Review for April 1867 . The flame that is most suited for the vowel experiments happens to be the parent of the family of sensitive flames, and is described in a little paper of mine in the Philosophical Magazine for March 1867.

Science Schools, South Kensington, July 27

\section{Aid to Private Research-Circulation of Scientific Memoirs}

THERE are many scientific students scattered through the country, as science-masters in schools, and in other capacities, who are willing and competent to undertake original researches in their special branches of science. The great obstacle to their attempting it is, in most cases, the cost of the necessary instruments. It is of course impossible to expect such apparatus as is required for original work to be supplied from the science funds of a school, these being properly applied to provide only what is requisite for teaching the pupils; so that if an investigation is to be attempted, the whole cost falls upon one who is probably just beginning life, and is quite unable to afford it. The work is therefore postponed for a considerable period, and perhaps is given up altogether. Now the Department of Science and Art grants aid in fitting up the schools which are under its control. If the Department would give similar aid towards purchasing expensive apparatus for research, or would allow competent workers to hire such instruments for the period they require them, much of the difficulty to which I have alluded would be removed. Many, I am sure, would be glad to avail themselves of the opportunity, and would willingly fulfil the conditions necessary to ensure the safety and proper use of the apparatus. I may remark that by this means it would probably be easy to organise to a certain extent the investigations to be carried on, and thus render the results far more valuable than they would be if isolated. Looking to the national importance and the unremunerative character of this kind of work, few will think that this appeal is exorbitant.

I wish to allude to another point, to which attention has already been drawn in your correspondence columns (NATURE, vol. viii. pp. 506, 550). A scientific man, unless he is fortunate enough to be within easy distance of a large scientific library, is practically debarred from reading even the most valuable memoirs that are published. Abstracts, indeed, he may see but these only serve to remind him that if he would get the original memoir for himself, he must purchase with it matter which is useless to him, but perhaps of the highest value to a worker in another branch. If these memoirs could be purchased in a separate form-or even if collections of papers bearing upon closely related subjects could be obtained-another cause of the costliness of science would be removed.

It has occurred to me that something ought to be done amongst ourselves to remedy our position as regards the transactions of the learned societies and the scientific periodicals. Could not a book-club be instituted, the members of which, upon paying a small annual subscription, should receive in turn the chief scientific periodicals? Or would it be more easy for a number of us who happen to take in difierent journals, to exchange them? If any of your readers should be inclined to co-operate with me in initiating either of these schemes, or to furnish any suggestions on the subject, I should be glad if he would communicate with me.
Sherborne, Dorset, July in
H. W. Lloyd TANner 